\title{
Comunidade escolar e modelagem matemática na educação matemática: uma reflexão
}

\section{Patrick Bellei}

patrickbellei@.gmail.com

orcid.org/0000-0002-4753-0290

Universidade Estadual do Oeste do Paraná (UNIOESTE), Foz do Iguaçu, Paraná, Brasil

\section{Tiago Emanuel Klüber} tiagokluber@gmail.com orcid.org/0000-0003-0971-6016 Universidade Estadual do Oeste do Paraná (UNIOESTE), Cascavel, Paraná, Brasil

\section{RESUMO}

Os documentos norteadores do estado do Paraná apresentam os encaminhamentos metodológicos necessários para a articulação dos conteúdos estruturantes da Matemática. Dentre eles, destaca-se a Modelagem Matemática considerada uma tendência metodológica da Educação Matemática. Nas pesquisas envolvendo esta tendência fica notável a existência de obstáculos para sua realização. Entretanto, questões voltadas para a comunidade escolar interna e externa, como pais, professores de outras áreas e a gestão escolar, são apenas tangenciados e até secundarizados frente a outros aspectos, como por exemplo, o currículo escolar. Este artigo foi desenvolvido por meio de uma meta-análise, levantando trabalhos e livros que abordam a Modelagem Matemática sem perder de vista o envolvimento da comunidade escolar com o ensino e a gestão escolar. Procuramos discutir a Modelagem Matemática para a Educação Matemática e suas relações com a comunidade escolar a partir da interrogação: que influências a comunidade escolar apresenta ao desenvolvimento de atividades de Modelagem Matemática para a Educação Matemática? A discussão aponta para a necessidade de aproximação de outros atores da comunidade escolar para que haja um melhor entendimento da utilização e direcionamento da Modelagem Matemática, de modo que esta tendência possa ser inserida efetivamente nas escolas. Apontamos a importância da presença e construção da gestão democrática para que o funcionamento da instituição de ensino seja conhecido e apreciado por todos, visando, principalmente, que a Modelagem Matemática seja conhecida por todos os atores envolvidos no processo de ensino.

PALAVRAS-CHAVE: Organização Escolar. Ações da gestão escolar. Obstáculo da Modelagem Matemática. 


\section{O CONTEXTO}

Uma primeira versão deste artigo foi publicada no XIV Encontro Paranaense de Educação Matemática, EPREM, no ano de 2017, contudo, foi revisado, aprofundando e ampliado para esta publicação. Desde a referida publicação, entende-se a importância de se destacar que ao utilizar a palavra atores, nos referimos "àquele que participa ativamente de um ato, de um acontecimento" (AULETE, 2011, p. 170). Outro aspecto importante é que ao utilizar no título "comunidade escolar", estamos considerando, além dos professores de matemática, professores de outras áreas, direção, equipe pedagógica, pais e alunos e, mesmo apresentando seções específicas para os pais, professores de outras áreas e gestão escolar, o texto tangencia a atuação dos outros atores citados. Nesse texto, especificamente, foram aprofundados estudos relativos à Modelagem Matemática na Educação Matemática e suas relações com os pares que atuam no ambiente escolar. Isso se deu especialmente com a participação e apreciação dos artigos publicados nos eventos específicos desta área.

A Modelagem Matemática, que é considerada uma tendência metodológica da Educação Matemática, no Brasil, pode ser aferida nos vários encontros voltados especificamente para este fim, como a Conferência Nacional Sobre Modelagem na Educação Matemática - CNMEM e o Encontro Paranaense de Modelagem na Educação Matemática - EPMEM, além de publicações voltadas a esta tendência em eventos de Educação Matemática em geral, como o Encontro Nacional de Educação Matemática - ENEM e o Encontro Paranaense de Educação Matemática - EPREM.

Além da evidência desta consolidação, documentos norteadores do processo de ensino da educação do estado do Paraná apresentam os encaminhamentos metodológicos necessários para a articulação dos conteúdos estruturantes "de forma a abandonar abordagens fragmentadas" (PARANÁ, 2008, p. 62) que, dentre as tendências apresentadas (resolução de problemas, modelagem matemática, mídias tecnológicas, etnomatemática, história da Matemática e investigações matemáticas), podem facilitar o processo de ensino.

As Diretrizes Curriculares da Educação Básica do Paraná apresentam a Modelagem Matemática como uma problematização de situações do cotidiano que "ao mesmo tempo em que propõem a valorização do aluno no contexto social, procura levantar problemas que sugerem questionamentos sobre situações de vida" (PARANÁ, 2008, p. 64). Neste sentido e, de posse dessas orientações, é razoável admitir que os docentes aprofundem seus estudos para um entendimento mais plausível sobre a sua utilização no âmbito das escolas, a fim de um preparo para que outros atores da escola possam ser parceiros de seu trabalho no decorrer do desenvolvimento das atividades. Leituras sobre as concepções de Modelagem Matemática de Barbosa (2001), Burak (2004), Almeida e Brito (2005), Biembengut e Hein (2005) e Caldeira (2005) são norteadoras para o entendimento do processo, uma vez que são pesquisadores em destaque na comunidade brasileira de Modelagem Matemática na Educação Matemática. Haja vista a quantidade de citações em diferentes artigos, como mostram Klüber e Burak (2014), bem como naquilo que concerne ao seu papel nucleador em pesquisas e práticas reconhecidas por esta mesma comunidade. 
É necessário, ainda, que os docentes assumam outras práticas de formação, que conforme García (1999) são embasadas em processos de formação ligados ao desenvolvimento organizacional das escolas, em outras palavras, a formação dos professores deve ser condicionada e condicionar a própria organização da escola. Um exemplo de prática de formação, e o tipo que nos referimos neste trabalho é a "Formação Continuada de professores em Modelagem Matemática na Educação Matemática" apresentada por Martins (2016) e Mutti (2016).

A partir desse pressuposto de formação, vinculado à estrutura escolar, tornase possível compreender que para adoção e implementação desta e de qualquer outra tendência, muitas ideias enraizadas e aceitas envolvendo as metodologias de ensino poderão ser alteradas e neste sentido outros atores, como é o caso da própria comunidade escolar deverão ser preparados e, minimamente, compreender, o modo como a Modelagem Matemática pode se operacionalizar na escola, levando-se em conta mudanças de práticas pedagógicas realizadas. Porém, a Modelagem Matemática pode ser vista pelos alunos "de uma forma extremamente prazerosa e que confere significativo conhecimento, seja na forma de conceitos matemáticos, seja sobre o tema que se estuda" (BIEMBENGUT, 2016, p. 28). Assim, o programa escolar

não se trata de um programa pronto e acabado, mas que pode ser construído pelos alunos com o auxílio do professor, de fora para dentro da escola, e não como, tradicionalmente, estamos acostumados a ver, somente da escola para os alunos (SILVEIRA; CALDEIRA, 2012, p.1023).

Com isso, torna-se necessário que no decorrer da formação, as práticas pedagógicas envolvendo a Modelagem Matemática sejam experienciadas e com elas surgirão as dificuldades apresentadas no desenvolvimento, que incidirão desde a escolha de um tema pelo professor (caso seja uma atividade "fechada") ou decorrente da escolha dos alunos (atividade "aberta") (BARBOSA, 2001), pelo cumprimento do currículo, até o ponderação e aceitação da comunidade escolar quanto ao modo de ensino que decorre da Modelagem, partindo do princípio que podem ser necessárias aulas externas à sala de aula, uso de laboratórios de informática ou considerando as composições de grupos e discussões acerca das atividades.

Sob essas condições, o docente pode se sentir desmotivado à continuidade do desenvolvimento de suas atividades. Entretanto, com a Modelagem Matemática apreciada como tendência da Educação Matemática e analisada por pesquisadores em relatos de experiência e na publicação de artigos que exibem as dificuldades apresentadas pelos professores em sua apropriação, é razoável notar que estes problemas podem ser minimizados. E é em virtude deste coletivo de pensamento ${ }^{1}$, expresso na produção escrita que circula na área, que se torna possível dar continuidade ao seu trabalho.

Porém, como mostra Barbosa (2002), os aspectos voltados para o tratamento de outros atores são, no máximo, tangenciados e, na maioria das vezes, secundarizados em relação a outros. (BELLEl; KLÜBER, 2016, p. 368). Na pesquisa de Barbosa (2002), envolvendo alunos de uma graduação em Matemática e suas práticas com a Modelagem Matemática, fica claro que alguns "receios apontados 
[para as dificuldades na utilização da Modelagem Matemática] são as expectativas e as possíveis reações dos demais atores da escola, como os próprios alunos, pais, supervisores e diretores" (BARBOSA, 2002, p. 11), apontando a necessidade de se aprofundar os estudos acerca dessa relação.

Considerando os aspectos expostos, procuramos empreender neste artigo uma discussão acerca do desenvolvimento da Modelagem Matemática para a Educação Matemática e as relações com a comunidade escolar, avançando com a interrogação: que influências a comunidade escolar apresenta ao desenvolvimento de atividades de Modelagem Matemática para a Educação Matemática?

Desde uma pesquisa bibliográfica, este artigo foi desenvolvido por meio do levantamento de artigos e livros que abordam a Modelagem Matemática, o envolvimento da comunidade escolar com o ensino e a gestão escolar, pois para Gil (1999) ao realizar a leitura nos documentos postos à pesquisa, deve-se investigar suas informações e seus dados e "estabelecer relações entre essas informações e dados e o problema proposto" (GIL, 1999, p. 85), além de verificar a consistência das informações.

O foco deste artigo no desenvolvimento de atividades de Modelagem Matemática, como reflexo da comunidade escolar (equipe gestora, professores, pais e alunos), decorre da inserção do primeiro autor na função de diretor e o desenvolvimento de pesquisas sobre a Modelagem Matemática dos dois autores. Sabemos que a Modelagem Matemática é muito mais complexa do que a apresentação destes grupos (alunos, pais, professores, equipe pedagógica e gestão escolar) separados. Ela deve ser apresentada de forma dependente entre todas estas categorias. Esta discussão visa corroborar com a pesquisa sobre Modelagem Matemática na Educação Matemática, com intuito de que o tema seja estudado por outros pesquisadores, promovendo a tendência entre professores de matemática.

Desta forma, a seção seguinte é resultado de um esforço dos autores em identificar o exposto nos textos sobre o envolvimento da comunidade escolar e o desenvolvimento de atividades de Modelagem Matemática, especificamente com os pais dos alunos e, logo após, com outros professores presentes no ambiente escolar e a própria gestão escolar.

Mesmo que alguns destes problemas não sejam exclusivos da Modelagem Matemática e que possam ser atribuídos a outras situações gerais da educação, as próximas seções apresentam algumas das características específicas do desenvolvimento de atividades envolvendo a Modelagem Matemática na Educação Matemática e sua relação com os pais, professores de outras áreas, a gestão escolar e particularidades a respeito dos outros atores citados. Especificamente, na próxima seção, apresentaremos uma breve síntese sobre a Modelagem Matemática na Educação Matemática. 


\section{MODELAGEM MATEMÁTICA E ALGUMAS ESPECIFICIDADES}

O ensino da Matemática tem se voltado para além das simples resoluções de listas de exercícios com foco no resultado final dos cálculos. Tem percorrido uma trajetória que vai além da compreensão da teoria. Esta maneira de ensinar abrange agora a natureza do problema (BIEMBENGUT, 2016). A partir dela busca-se "[...] despertar no aluno o interesse por tópicos matemáticos que ele ainda desconhece, ao mesmo tempo que aprende a arte de modelar, matematicamente" (BIEMBENGUT, 2016, p. 18), em meio a situações-problema advindas de suas próprias interações sociais.

Mais do que isso, Kaiser e Sriraman (2006) discorrem sobre algumas perspectivas da Modelagem Matemática, nas quais facilmente se destacam outros benefícios para a inserção da Modelagem Matemática em sala de aula, sendo elas as perspectivas: realística, contextual, sociocrítica, epistemológica, cognitiva e educacional.

Ao se considerar a perspectiva realística, as situações-problema são desenvolvidas com base em atividades da indústria ou ambientes de trabalho, com foco na resolução de problemas aplicados a situações reais. A contextual possui o propósito de contextualizar conteúdos matemáticos considerando aspectos motivacionais dos alunos por meio de situações que são significativas a eles. A sociocrítica apresenta situações matemáticas que possam levar o estudante a um pensamento crítico sobre a realidade que está presente, convidando os alunos a produzirem conhecimento reflexivo acerca do conteúdo estudado (BARBOSA, 2003). A epistemológica é a resolução de situações-problema que proporcionam o desenvolvimento específico de conceitos matemáticos. A cognitivista é interessada na averiguação dos processos cognitivos desenvolvidos pelo aluno durante a resolução da situação-problema. E a educacional integra o desenvolvimento de modelos matemáticos ${ }^{2}$ ao ensino da Matemática. Ressalta-se que as perspectivas apresentadas, por muitas vezes são combinadas, com intuito maior de melhoria da qualidade do ensino da Matemática.

Além disso, todas essas perspectivas levam a encaminhamentos diferentes dos tradicionalmente utilizados por diversos professores de Matemática.

\footnotetext{
Mesmo admitindo que a Matemática esteja sendo construída nas interações sociais, ou mesmo que admitamos que ela seja constituída pelas regras e convenções daqueles escolhidos para serem os representantes dessa matemática, o que existe ainda nas nossas escolas é "uma única" matemática escolar que está posta nos currículos, ou seja, apenas como determinadas regras e convenções ditas universais - aquilo que comumente denominamos de lista de conteúdos - (CALDEIRA, 2009, p. 43).
}

Porém, as Diretrizes Curriculares da Educação Básica de Matemática apontam um percurso diferente deste, considerando que, "os conteúdos propostos [no documento] devem ser abordados por meio de tendências metodológicas da Educação Matemática que fundamentam a prática docente" (PARANÁ, 2008, p. 63). Dentre elas a Modelagem Matemática. Entende-se também que o documento ao fazer referência a "abordagens fragmentadas" (PARANÁ, 2008, p. 62), indica que o ensino da Matemática deve ocorrer de forma a dar continuidade e sentido 
aos conteúdos para os estudantes. Este é um aspecto importante para a inserção da Modelagem Matemática em sala de aula já, que "o modelo matemático buscado deverá ser compatível com o conhecimento do aluno, sem desconsiderar novas oportunidades de aprendizagem, para que ele possa sofisticar a matemática conhecida a priori" (PARANÁ, 2008, p. 65).

Mas inserir a Modelagem Matemática em sala de aula requer seu conhecimento, seja por meio de leituras, da formação inicial ou da formação continuada e, em decorrência disso, construir apresentações adequadas, desconstruir inadequadas e reconstruir aquelas que se aproximem de sua utilização. Sua inserção transforma ainda o modo como o trabalho dos profissionais de Matemática é realizado na escola perante a organização dela.

É necessário compreender que uma nova maneira de organizar a sala de aula será requisitada, visto que os alunos serão levados ao debate dos conteúdos, sempre organizados em grupos. Mas a organização diferenciada da sala de aula não é um problema para a utilização do Modelagem Matemática, o que se esta em questão é a influência de outros profissionais perante a observação destas ações que podem gerar desconfortos, caso sejam encaradas como formas de não realizar seu trabalho e, este é um ponto a ser superado.

Um segundo ponto é como estas ações, sejam no interior das escolas, ou mesmo fora dela, por meio da pesquisa dos assuntos estudados, podem ser entendidos pela comunidade escolar, interna e externa, quanto ao que se esta sendo estudado, considerando que há um conceito de que o ensino da Matemática continua pautado no ensino de regras e resolução de problemas visando a memorização. Assim,

\footnotetext{
é possível dizer que na condução das atividades de Modelagem Matemática, a memorização e a repetição não são tomadas como aspectos centrais para a aprendizagem dos conteúdos matemáticos, pois eles são contemplados na medida em que os alunos necessitam deles para avançar no processo de resolução dessas situações (MUTTI, 2016, p. 69)
}

O que se percebe é que a comunidade escolar espera que a escola produza resultados e estes apenas aparecerão mediante a um formato de ensino tradicional, concebido por muitas pessoas e, juntamente a isso, grande parte das avaliações continuam com o modelo do ensino com base na memorização. Porém, documentos como as Diretrizes Curriculares da Educação Básica (2008) apontam para a utilização de tendências da Educação Matemática como forma de melhoria na qualidade do ensino.

Outro ponto é como o currículo escolar é afetado com a Modelagem Matemática e como a comunidade escolar pode analisar o trabalho com os conteúdos, pois com sua utilização, os assuntos tratados tendem a evocar diferentes conteúdos e estes podem não seguir a ordem pré-estabelecida, posta no currículo ou no livro didático. Porém, autores como Blum e Niss (1991); Almeida, Silva e Vertuan (2013); e Biembengut (2016) apontam algumas formas para integrar a Modelagem Matemática ao currículo escolar. 
No caso de Biembengut (2016) pode-se escolher os modelos a serem trabalhados conforme a necessidade dos conteúdos, sendo necessário que se tenha vários modelos disponíveis. Almeida, Silva e Vertuan (2013) apontam como uma possibilidade aproveitar os conteúdos que estão sendo trabalhos, inserindo situações de Modelagem Matemática. Porém, neste caso é necessário que o professor disponibilize seu tempo para explicar conteúdos que podem surgir e que estão fora do currículo daquela turma. Para Blum e Niss (1991), pode-se optar pela separação, que consiste em ministrar cursos extraclasse, ou a combinação, que consiste em utilizar a Modelagem Matemática como forma de introduzir conceitos. Burak (1998) sugere que haja uma organização dos conteúdos em unidades de conteúdos articuladas ao tema que está sendo tratado, conforme a necessidade advinda das resoluções, ministrando [...] não simplesmente o conteúdo necessário à resolução, principalmente no nível da educação básica, para o qual o autor parece se voltar predominantemente, mas ensinar todo um conteúdo [...] (KLÜBER; BURAK, 2008, p. 23)

Neste sentido, a Modelagem Matemática altera a prática do professor, tanto nas suas ações diferenciadas do ensino tradicional que podem ser encaradas por terceiros como uma forma de não executar seu trabalho, como na forma em que o conteúdo é exposto. Suas ações diferenciadas incidem sobre a organização de espaço da sala de aula e mesmo fora dela, por meio da pesquisa ou formação de grupos; utilização de outros ambientes como o laboratório de informática; os registros das atividades que não seguem o padrão tradicional de ensino; dentre outros. Já, quanto à exposição do conteúdo, pode-se considerar que a maneira não linear de apresentação dele, de forma diferente da ordem e lista apresentados tanto nas diretrizes como no livro didático, sofre resistências da comunidade escolar, talvez pela falta de conhecimento ou por seguir um padrão de acompanhamento advindo de suas relações com a Matemática, historicamente (SILVEIRA; CALDEIRA, 2012).

Para tentar clarificar estas ideias e aprofundar estas discussões, apresentamos nas seções seguintes uma meta-análise do tema em questão, considerando tópicos relacionados aos pais dos alunos e aos professores de outras áreas e a gestão escolar. É uma investigação pautada em comparações e análises dos dados primários de pesquisas, tomadas como significativas em relação ao tema posto sob foco. $\mathrm{O}$ alvo é desenvolver um conhecimento teórico que apresente um nível de abstração mais elevado em relação às sínteses interpretativas dos estudos primários, visando à maior possibilidade de aplicações em situações práticas (ZIMMER, 2006 apud BICUDO, 2014).

Para as duas próximas seções, utilizando no título "responsáveis externos", nos referimos aos pais, familiares ou incumbidos a desempenhar a função de responsabilidade pelas crianças e/ou adolescentes; e "responsáveis internos" como professores de outras áreas e gestão escolar.

\section{DOS RESPONSÁVEIS EXTERNOS} (PARANÁ, 2008) que recomenda a tendência da Modelagem Matemática para a 
Educação Matemática como uma forma de apresentar a disciplina de Matemática para os alunos problematizando as situações do cotidiano, é importante destacar que estas "situações do cotidiano", fazem parte do próprio ambiente familiar. Afinal

os alunos chegam à escola marcados pela diversidade, reflexo dos desenvolvimentos cognitivo, afetivo e social, evidentemente desiguais, em virtude da quantidade e qualidade de suas experiências e relações sociais, prévias e paralelas à escola (DAYRELL, 1996, p. 5).

Considerando que uma parte do desenvolvimento dos estudantes é advinda das relações sociais com os pais e ponderando que os pais possuem seus conhecimentos marcados por relações históricas, é necessário aproximá-los da escola. A participação efetiva dos pais na escola com intuito de melhorias na qualidade do ensino proporciona a discussão de duas situações, conforme Paro (2007), uma que aborda a escola como única responsável pelo ensino e outra que trata sobre a concepção dos pais quanto ao desempenho escolar.

A primeira trata de um fundamento contrário a esta participação, de que a função de ensino cabe exclusivamente à escola e que os pais não devem influenciar nesta decisão. Em decorrência disso cabe à escola oferecer educação de qualidade sem que os pais tenham que trabalhar para isso. Assim, se a função de ensino é exclusivamente da escola, não cabe aos pais a preocupação com a qualidade que as aulas são proporcionadas, porém entramos em uma contradição, pois como o autor mostra é impossível que a educação aconteça sem a participação destes e essa parceria necessariamente precisa ocorrer.

A segunda trata da compreensão dos pais quanto à medida do desempenho escolar, que em geral entendem que pode ser medido apenas pelos exames e provas convencionais (internas e externas) além dos vestibulares. Este desempenho está totalmente ligado ao acompanhamento do currículo, que com a utilização da Modelagem Matemática tende a ser não linear. Desta forma, os pais não conseguem realizar um acompanhamento dos conteúdos que estão sendo abordados e analisam como teores não trabalhados, impossibilitando (supostamente) os filhos de realizar avaliações externas à escola, como vestibulares por exemplo.

Com a pressão existente pelos pais para que os filhos realizem uma produção através de continuidade dos conteúdos, o entendimento é de que não se está aprendendo o que realmente é preciso e, com isso, o conteúdo necessário a se apreender para vestibulares não se torna suficiente (BELLEI; KLÜBER, 2016, p. 370).

Ademais, Paro (2007) defende a participação dos pais a partir da primeira aproximação deles no estudo dos filhos, incentivando o estudo no ambiente escolar, além do acompanhamento em casa das atividades desenvolvidas como tarefa. Essa discussão nos remete à preocupação que os pais podem ter com a Modelagem Matemática, pois "para os pais a Matemática dita universal permite controlar os estudos dos seus filhos por meio dos cadernos e das tarefas" (SILVEIRA; CALDEIRA, 2012, p. 1040). As tarefas desenvolvidas com Modelagem costumam ser diferentes das tradicionalmente exigidas pelos professores, 
comumente com listas de exercícios, onde a principal função é a memorização. As atividades de Modelagem Matemática envolvem pesquisas, entrevistas ou visitas a locais para buscas de informações, com vistas a resolver os problemas que serão elaborados na escola. Além disso, com uma mudança na forma de ensino dos professores, os pais podem se sentir inseguros para participar desse processo, pois não sabem a melhor maneira de colaborar com os filhos.

Além dos pais, outros atores também podem influenciar o desenvolvimento desta tendência no contexto escolar. Professores e gestores podem interferir no processo desenvolvido no interior das escolas e, com isso, destinamos a seção seguinte a abordar as relações de professores que lecionam outras disciplinas e a gestão escolar.

\section{DOS RESPONSÁVEIS INTERNOS}

Ao implementar a Modelagem Matemática no interior das escolas, através das atividades realizadas com os alunos, geralmente em grupos, modificam-se as estruturas organizacionais da escola. Nesse sentido, "Muda-se uma estrutura de escola tradicional, de costumes e de formas de ensino que merecem ser explicados para outros atores participantes e presentes no processo de ensino" (BELLEl; KLÜBER, 2016, p. 375, SIC), os alunos são envolvidos em discussões e organizações diferentes no interior da sala de aula, o que pode aparentar, para outros professores de turmas com salas de aula próximas ou que acompanham o processo de fora, um sentido de desorganização do espaço escolar. Além disso, outras situações podem aparecer. Bisognin e Bisognin (2009) apresentam como resultado de uma pesquisa com Modelagem, um professor de outra área que critica o professor de estatística ao utilizar uma pesquisa eleitoral para base de seu trabalho. Isso mostra um distanciamento dos propósitos que deveriam ser comuns à instituição de ensino.

Conforme Dayrell (1996) a escola é constituída por um confronto de interesses. Por um lado encontra-se a própria organização escolar quanto à estrutura de funcionamento e de outro se encontram as relações sociais existentes entre os pares, que fazem da escola um local de constante construção social.

\footnotetext{
Apreender a escola como construção social implica, assim, compreendêla no seu fazer cotidiano, onde os sujeitos não são apenas agentes passivos diante da estrutura. Ao contrário, trata-se de uma relação em contínua construção, de conflitos e negociações em função de circunstâncias determinadas (DAYRELL, 1996, p. 2).
}

Esta trama de relações entre os sujeitos é realçada entre as alianças e os conflitos estabelecidos como forma de alcançar seus objetivos. As alianças podem ocorrer quando professores decidem se organizar para promover uma forma diferenciada de ensino de Matemática, por exemplo, casos de formação continuada em Modelagem Matemática, como mostram Martins (2016) e Mutti (2016). Já os conflitos ocorrem quando os objetivos dos professores estão ligados às relações de poder atreladas à estrutura de funcionamento da escola, visando a 
conquista de regalias ou a manutenção de padrões aceitos por meio da gestão escolar.

Organizar aulas em forma de debate pode levar outros professores ao incômodo, considerando as conversas entre os alunos. Esse tipo de organização pode aparentar desordem, pois conflita com a tradição vigente na escola, na qual os alunos são postos em filas e apenas ouvem ou copiam as lições do professor, questionando, raramente, quando há dúvidas. Consequentemente a esta questão, devemos levar em conta, ainda, que as salas de aula continuam com uma característica física de construções advindas de séculos atrás, impregnada pela ideia de controle dos alunos, o que dificulta que o ensino pautado pela Modelagem Matemática se efetive. Parte de uma renovação do pensamento pedagógico na segunda metade do século XVIII e em parte do século XIX.

Essa nova escola submete professores e alunos a um modelo de educação altamente especializado no controle e disciplinamento de "corpos e espíritos", a regras e ritos; passa a utilizar elementos de controle, como é o caso das chamadas regras e comportamentos que permanecerão presentes na escola atual." (ARRIADA, E.; NOGUEIRA, G. M.; VAHL, M. M., 2012, p. 52).

Esta forma de "desorganização" pode levar ao declínio da adoção da Modelagem Matemática nas escolas, considerando as diferentes reações advindas da gestão escolar, de boas conduções e práticas que assegurem um bom andamento pedagógico.

Além disso, organizar o trabalho para acolher a Modelagem Matemática, solicita preparação de outros atores inseridos no espaço escolar, uma vez que

[...] os professores precisam lidar com os desafios provenientes das pressões advindas da gestão escolar e dos colegas professores, que [...] exigem o cumprimento do currículo e mostram certa desconfiança com a validade e seriedade do trabalho com a Modelagem (MUTTI, 2016, p. 94).

Mutti (2016) considera que a gestão escolar e ainda outros atores do ambiente escolar podem encarar o trabalho com as tendências da Educação Matemática como um indicador de ausência de compromisso do professor para com o currículo escolar e o planejamento, pois, "a prática pedagógica do professor de Matemática ainda está intimamente atrelada ao livro didático e as políticas públicas de avaliação em larga escala" (MUTTI, 2016, p. 125).

Conforme Paro (2012) as relações sociais existentes na escola sustentam relações diretas com uma escola ligada ao capitalismo, onde os empregados mantêm aspectos de subordinação com seus superiores. Ainda que não seja a única possibilidade de expressão escolar, a ideia apresentada é a de eliminação do pensamento crítico com vistas apenas ao trabalho como forma de maior produção. Nesta relação, encontram-se gestores preocupados com a visão política que está sendo imposta pelos ambientes externos à escola, em forma de um ceticismo metafísico ${ }^{1}$, acreditando apenas no que está perante a sua visão, sendo chamado 
habitualmente de positivismo, limita-nos ao positivamente dado, aos fatos imediatos da experiência, fugindo de toda a especulação metafísica (HESSEN, J., 1980). A imagem apresentada pelos gestores encontra-se pronta perante a percepção externa, limitando-se a meros fatos da experiência, uma imagem na qual imperam o silêncio e determinada organização linear para manter as aparências. A imagem do gestor encontra-se pronta, num contexto em que políticos e população, no geral, acreditam apenas no que aparece "imediatamente aos seus olhos". É incoerente, porém, acreditar em apenas um modelo de gestão escolar que se mantém preocupada com a imagem delimitada fora dos portões da escola. A forma de trabalho que envolve as relações sociais entre professores e diretores tem conotações subjetivas, dependendo dos objetivos de cada gestão.

\begin{abstract}
No contexto dessa concepção dominante, é comum atribuir-se a todo e qualquer problema uma dimensão estritamente administrativa, desvinculando-o do todo social no qual tem lugar suas causas profundas, e enxergando-o apenas como resultante de fatores como a inadequada utilização dos recursos disponíveis, a incompetência das pessoas e grupos diretamente envolvidos, a tomada de decisões incompatíveis com seu equacionamento e solução, e outras razões que podem facilmente ser superadas a partir de uma ação administrativa mais apropriada (PARO, 2012, p. 165).
\end{abstract}

A problemática parece situar-se sempre em falhas de natureza administrativas, com incapacidades para se ajustar a novas exigências e novos problemas cotidianos. Porém, Paro (2012) aponta que este ajuste requer ações planejadas e organizadas, que sejam realizadas por pessoas qualificadas para atender as demandas qualitativas e quantitativas da sociedade. A escola não pode ser tratada, apenas, por meio de ações administrativas como se fosse empresa, como se os mesmos métodos fossem utilizados com mesmos êxitos. É preciso, antes de qualquer outra coisa, que a escola seja encarada por meio de seus problemas sociais. Se o objetivo é a melhoria da qualidade de ensino, o gestor analisará estas relações para definir estratégias que supram as necessidades. Caso contrário, o incômodo advindo de outros professores poderá romper as relações com a Modelagem Matemática, pois de certo modo, ela pode contrapor-se ao modelo de produtividade, estritamente vinculado a resultados.

\title{
UM DEBATE
}

É inegável que os professores de Matemática necessitam de formação continuada para a melhor apreciação da Modelagem Matemática, porém, influências advindas das relações sociais entre pais e alunos/ professores e professores/ professores e gestores juntamente com as relações dos gestores com as próprias políticas públicas, são situações que podem causar desequilíbrio para a Educação Matemática no que tange a utilização da tendência de Modelagem Matemática e seu desenvolvimento. Para Santos (2004),

a base de organização da gestão da educação e da escola não será piramidal e hierarquizada, mas adotará um desenho circular que pressupõe a interrelação entre os atores sociais e uma partilha de poder, o que implica corresponsabilidade nas ações da escola (p. 4). 
Com base nessa consideração, destacam-se os sujeitos da comunidade escolar como parceiros importantes para o processo de ensino fundado em uma participação ativa e responsável com vistas a alcançar juntamente com outros pares os objetivos da escola.

Esta participação da comunidade escolar tem bases tanto na fiscalização dos recursos quanto na participação das ações que envolvem o ensino/aprendizagem,

trata-se da necessária intercomunicação entre educadores escolares e os pais ou responsáveis do estudante para promover um mínimo de compatibilidade entre a forma de educar de ambas as partes, de modo a incrementar a eficiência do ensino (PARO, 2016, p. 199).

É evidente que a população está cada vez mais sobrecarregada e sem tempo para o acompanhamento escolar, contudo, para Paro (2016) uma melhoria significativa nos processos de ensino remetem que escola e comunidade devem ter claros e seguir os mesmos objetivos. As equipes gestoras devem almejar a promoção de ações que ensejem aos pais as informações necessárias para o entendimento dos objetivos traçados para que possam desenvolver o acompanhamento coerente. De certa forma, a participação da comunidade escolar no processo de ensino tem ligações diretas com a gestão democrática, ou ainda, "a gestão democrática deve implicar necessariamente a participação da comunidade" (PARO, 2016, p.22). Para este autor, é necessária uma maior precisão deste conceito de participação, com relação à tomada de decisões ou determinada autonomia de pensamento. É importante que esta participação não seja tomada apenas com a execução, como fim, mas com o desenvolvimento, com o meio do processo. Ações deste nível desencadeiam atitudes que promovem a inserção de novas tendências para melhoria do processo de ensino, mostrando a importância da gestão democrática.

No que concerne à Modelagem Matemática e a falta de entendimento dos pais, cabe aos gestores administrar a maneira que as informações serão repassadas. Após o conhecimento dos professores sobre o desenvolvimento da Modelagem Matemática, um primeiro passo é a informação que será repassada para a equipe pedagógica sobre como se dará o trabalho, visto que será esta equipe a responsável por receber e acompanhar o planejamento. É imprescindível que os gestores recebam o mínimo de informação dos professores que estão envolvidos com a Modelagem Matemática para iniciar o trabalho, pois os professores de Matemática devem, neste momento, estar capacitados para isso. É importante que o gestor leve em consideração os objetivos da escola, partindo do pressuposto que a formação social dos alunos é prioridade e que a exposição política não deva ser almejada. As informações poderão ser repassadas através de reuniões gerais com pais, equipe pedagógica e professores, para que estes tenham as informações necessárias deste processo. É necessário que os pais estejam cientes dos procedimentos utilizados com o uso desta tendência, não necessariamente aprender sobre a sua utilização, mas sim entender o processo de forma geral, para que suas dúvidas sejam sanadas a ponto de entenderem os benefícios de sua utilização. Com o conhecimento dos gestores sobre o processo, eles serão capazes de auxiliar e apoiar os professores de Matemática da melhor 
maneira possível para a construção deste procedimento, incentivando sua utilização.

Ainda que essas recomendações pareçam genéricas e pareçam servir a qualquer outra inovação pedagógica, elas revelam algo mais fundo sobre a organização escolar e o desconforto trazido pelas tarefas de Modelagem Matemática. A organização escolar, ainda que seja essencialmente histórica, não se vê desse modo, assumindo, muitas vezes, o compromisso da manutenção do status quo. A Modelagem, conforme defendida por diferentes autores, dentre eles Biembengut (2016), Almeida, Silva e Vertuan (2013), Barbosa (2001, 2002), Caldeira (2005, 2009), rompe com o paradigma vigente na escola. Sendo assim, causa um estranhamento muito sobressaliente aos atores escolares, uma vez que não faz parte e, muitas vezes, sequer tangencia aspectos daquilo que é conhecido por eles. Essa mudança na rotina da escola trazida de forma mais ressaltada por uma tendência aberta, crítica e que questiona esse status quo, mais do que o confirma (CALDEIRA, 2005), requer um esforço mais intenso da parte dos professores para que resistam e dialoguem com a gestão escolar.

Sem dúvida, professores de outras áreas compõem esse cenário mais amplo e devem ser orientados sobre os encaminhamentos que a tendência de Modelagem Matemática irá tomar. Bisognin e Bisognin (2009) apontam que isso pode ser feito por meio da apresentação de relatos de experiência dos professores de Matemática para os professores de outras áreas. Além disso, Bisognin e Bisognin (2012) esclarecem que "o caráter interdisciplinar da Modelagem [pode ser], também, um fator que gere insegurança, pois o uso de Modelagem pressupõe saber Matemática e ter conhecimento de outras áreas" (BISOGNIN E BISOGNIN, 2012, p. 1061, adaptação nossa). Isso mostra ainda mais, que romper com a visão disciplinar da escola e que um trabalho para rescindir com essa visão é necessário. Assim,

\footnotetext{
o ato de participar pode ser expresso em diversos níveis ou graus, desde a simples informação, avançando para opinião, voto, proposta de solução de problemas, acompanhamento e execução das ações, e que deve gerar um sentimento de co-responsabilidade sobre as ações. O que importa, então, é que os atores sociais da escola tenham conhecimento e clareza do sentido do termo, da responsabilidade que o mesmo encerra e das formas possíveis de participação no interior de uma gestão democrática para que, assim, eles possam vivenciar o processo (ARAÚJO, 2003, p. 32).
}

A participação efetiva da comunidade escolar traz ainda "contradições relacionadas ao conceito de participação tanto em relação ao poder político, como também no que concerne à própria amplitude conceitual do termo" (ARAÚJO, 2003 , p. 35). A contradição nessa participação da comunidade encontra-se na clareza que os gestores possuem de gestão democrática, pois alguns interesses coletivos podem ser coagidos em função de interesses políticos. As relações políticas externas à escola podem ser apreciadas na preocupação dos gestores quanto à "imagem" que estão passando para a população externa à escola.

Para finalizar, é importante destacar que os objetivos traçados pelas instituições de ensino devem ser almejados por toda a comunidade escolar para que as ações a serem desenvolvidas sejam de sucesso. Aliado isso, os gestores 
escolares precisam se manter atentos ao interior das escolas para que suas ações não sejam influenciadas exclusivamente e de modo acrítico por visões políticas apresentadas interna ou externamente. A Modelagem Matemática, mesmo consolidada no âmbito da pesquisa, necessita de atenção de outros atores envolvidos com o processo de ensino para que seja efetivamente inserida na escola.

\section{REFLEXÕES}

Muitos são os trabalhos que apresentam argumentos para a inserção da Modelagem na escola. Outros apresentam considerações acerca das dificuldades e obstáculos expostos com sua utilização. $\mathrm{O}$ que procuramos apresentar neste artigo, a partir dos estudos abordando a Modelagem Matemática e da vivência da realidade da gestão escolar, foram situações que, de certa maneira, emergem quando a Modelagem é implementada em contexto escolar, independentemente da concepção assumida.

A superação destes obstáculos requer que se avance na forma como a Matemática é concebida, sendo crucial construir um novo paradigma de ensino. Junto com este progresso é indispensável que a concepção dos pais também se desenvolva, acompanhando as mudanças, sendo necessário que eles tenham conhecimento das ações desempenhadas pelos professores com intuito de melhoria na qualidade do ensino e consequentemente possam estar mais presentes na escola, sendo parceiros dela.

Essas transformações parecem também não ser interpretadas por outros profissionais da escola como algo que possa trazer benefícios para a qualidade da educação, não só da Matemática, mas de outras disciplinas, considerando que muitas destas atividades acabam sendo interdisciplinares. É necessário que outros profissionais reconsiderem as práticas de ensino diferentes do ensino tradicional para que possam trabalhar juntos pela escola, buscando um ensino que esteja fortemente ligado a realidade do aluno.

Os gestores escolares são os profissionais que podem propiciar o trânsito das informações, tanto para a comunidade escolar externa quanto para a interna, resolvendo os conflitos que a utilização da Modelagem Matemática pode trazer para os pais ou outros profissionais. Essa incumbência é de suma importância para que esta tendência tenha maior espaço na escola e, além disso, contribua para os processos da adoção da gestão democrática.

A Modelagem Matemática carece de pesquisas de desenvolvam não apenas atividades a serem realizadas, mas o que se mostra de sua utilização em sala de aula e como isso afeta a escola como um todo. 


\title{
School community and mathematical modeling in mathematics education: a reflection
}

\begin{abstract}
The documents that guide the teaching process of State Education present the necessary methodological references for the articulation of structuring content of mathematics. Among them is the mathematical modeling. Researches involving this trend point out some obstacles involved in the development. However, issues facing the school community external and internal as parents, teachers from other areas and school management, are only tangencial and even secondary regarding other aspects, such as, the curriculum. This article was developed based on a meta-analysis by collecting papers and books that deal with the mathematical modeling, without losing sight in the involvement of the school community with the teaching and school management. We carried out a discussion about the development of the mathematical modeling for the mathematics education and its relations with the school community which brings the question: which influences does the school community present to the development of activities of Mathematical Modeling for the Mathematics Education? The discussion points to the approximation of other actors in school community, in order to have a better understanding of the use and routing of Mathematical Modeling, so that this trend may be implemented with better results in schools. It is highlighted the importance of the presence and the construction of democratic management to ensure that the functioning of the educational institution is known and appreciated by all, aiming mainly that Mathematical Modeling is known by all the actors involved in the process of teaching.
\end{abstract}

KEYWORDS: School Organization. School management actions. Obstacle of Mathematical Modeling. 


\section{NOTAS}

${ }^{1}$ Expressão utilizada por Ludwick Fleck (1896-1961) ao se referir a ideias compartilhadas por um grupo de pesquisadores que adotam as mesmas práticas e, de certa maneira, compartilham o pensamento e as interpretações de fatos.

${ }^{2}$ [...] a resolução de um problema, em geral quando quantificado, requer uma formulação matemática detalhada. Nessa perspectiva, um conjunto de símbolos e relações matemáticas que procura traduzir, de alguma forma, um fenômeno em questão ou problema de situação real, denomina-se "modelo matemático" (BIEMBENGUT; HEIN, 2016, p. 12).

\section{REFERÊNCIAS}

ALMEIDA, L. M. W.; BRITO, S. Atividades de modelagem matemática: que sentido os alunos podem Ihe atribuir?. Ciência \& Educação, v. 11, n. 3, p. 483-497, 2005.

ALMEIDA, L. M. W; SILVA, K. P.; VERTUAN, R. E.. Modelagem Matemática na Educação Básica. São Paulo: Contexto, 2013.

ARAÚJO, A. V. Política Educacional e Participação Popular: um estudo sobre esta relação no município de Camaragibe - PE. Recife: UFPE, 2003. 143 p. Dissertação de Mestrado. Dissertação, Mestrado.

ARRIADA, E.; NOGUEIRA, G. M.; VAHL, M. M.. A sala de aula no século XIX: disciplina, controle, organização. CONJECTURA: filosofia e educação, v. 17, n. 2, p. 37-54, 2012.

AULETE, C.. Novíssimo Aulete dicionário contemporâneo da língua portuguesa. Rio de Janeiro: Lexikon, 2011.

BARBOSA J. C. Modelagem na Educação Matemática: contribuições para o debate teórico. In: Reunião anual da ANPAD, 2001, Caxambu, Anais... Rio de Janeiro: ANPAD, 2001, p. 1-15.

BARBOSA J. C. Modelagem matemática e os futuros professores. In: Reunião Anual da ANPAD, 2002, Caxambu. Anais... Rio de Janeiro: ANPED, 2002, p. 1-16.

BARBOSA J. C. Modelagem matemática e a perspectiva sócio-crítica. Seminário Internacional de Pesquisa em Educação Matemática, v. 2, p. 1-13, 2003. 
BELLEI, P; KLÜBER, T. E. Modelagem Matemática na Educação Matemática e a Gestão Escolar: Uma discussão - Encontro Paranaense de Modelagem na Educação Matemática. Anais... Londrina: UEL, UTFPR, 2016, p. 367-378.

BICUDO, M. A. V.. Meta-análise: seu significado para a pesquisa qualitativa. Revemat: revista eletrônica de educação matemática, v. 9, p. 7-20, 2014.

BIEMBENGUT, M. S.; HEIN, N. Modelagem matemática no ensino. São Paulo: Editora Contexto, 2005.

BIEMBENGUT, M. S.; HEIN, N. Modelagem matemática no ensino. São Paulo: Editora Contexto, 2016.

BISOGNIN, E.; BISOGNIN, V.. Repercussões da prática de modelagem matemática no exercício profissional da docência. In: IV Seminário Internacional De Pesquisa Em Educação Matemática. Anais... Brasília: Unifra, 2009, p. 1-16.

BLUM, W.; NISS, M.. Applied mathematical problem solving, modelling, applications, and links to other subjects-State, trends and issues in mathematics instruction. Educational studies in mathematics, v. 22, n. 1, p. 37-68, 1991.

BURAK, D. Formação dos pensamentos algébricos e geométricos: uma experiência com modelagem matemática. Pró-Mat. Paraná, Curitiba, v. 1, n. 1, p. 32-41, 1998.

BURAK, D. Modelagem Matemática e a Sala de Aula. In: Encontro Paranaense em Educação Matemática, 1, 2004, Londrina. Anais... Londrina: UEL, 2004. p. 1-10.

CALDEIRA, A. D. A modelagem matemática e suas relações com o currículo. In: IV Conferência Nacional sobre Modelagem e Educação Matemática - CNMEM. Anais... Feira de Santana, 2005, p. 1-15.

CALDEIRA, A. D. Modelagem Matemática: um outro olhar. Alexandria: Revista de Educação em Ciência e Tecnologia, v. 2, n. 2, p. 33-54, 2009.

DAYRELL, J. A escola como espaço sócio-cultural. Múltiplos olhares sobre educação e cultura. Belo Horizonte: UFMG, p. 136-161, 1996. 
GIL, A. C.. Métodos e técnicas de pesquisa social. 5. ed. São Paulo: Atlas, 1999.

HESSEN, J.. A possibilidade do conhecimento. In: Teoria do conhecimento. Coleção Stvdivm. Temas filosóficos, jurídicos e sociais, Portugal: Editora Coimbra, 1980, p. 37-57.

KAISER, G.; SRIRAMAN, B. A global survey of international perspectives on modelling in mathematics education. The International Journal on Mathematics Education, v. 38, n. 3, p. 302-310, 2006.

KLÜBER, T. E.; BURAK, D. Sobre a pesquisa em Modelagem na Educação Matemática brasileira. Revista Diálogo Educacional (PUCPR. Impresso), v. 14, p. 143, 2014.

KLÜBER, T. E.; BURAK, D. Concepções de modelagem matemática: contribuições teóricas. Educação Matemática Pesquisa, v. 10, n. 1, 2008.

MARTINS, S. R..Formação continuada de professores em modelagem matemática na educação matemática: o sentido que os participantes atribuem ao grupo. Foz do Iguaçu: Unioeste, 2016, 139 p. Dissertação (Mestrado em Ensino).

MUTTI, G. S. L.. Práticas pedagógicas de professores da Educação Básica num contexto de formação continuada em Modelagem Matemática na Educação Matemática. Foz do Iguaçu: Unioeste, 2016, 236 p. Dissertação (Mestrado em Ensino).

PARANÁ, Diretrizes Curriculares da Educação Básica. Matemática. Curitiba: SEED, 2008.

PARO, V. H. Qualidade do ensino: a contribuição dos pais. São Paulo: Xamã, 2007.

PARO, V. H. Administração Escolar: introdução crítica. São Paulo: Cortez, 2012.

PARO, V. H. Gestão Democrática da Escola Pública. São Paulo: Cortez, 2016.

SANTOS, A. L. F. dos. Gestão democrática da escola: bases epistemológicas, políticas e pedagógicas. Estado e Política Educacional, n. 05, 2004. 
SILVEIRA, E.; CALDEIRA, A. D.. Modelagem na Sala de Aula: resistências e obstáculos. Bolema, v. 26, n. 43, p. 1021-1047, 2012.

Recebido: 09 mar. 2018

Aprovado: 03 set. 2018

DOI: 10.3895/actio.v3n3.7695

Como citar:

BELLEI, P.; KLÜBER, T. E. Comunidade escolar e modelagem matemática na educação matemática: uma reflexão. ACTIO, Curitiba, v. 3, n. 3, p. 317-335, set./dez. 2018. Disponível em:

$<$ https://periodicos.utfpr.edu.br/actio>. Acesso em: XXX

Correspondência:

Patrick Bellei

Rua Nadyr Maggi, n.416, Centro, São Miguel do Iguaçu, Paraná, Brasil.

Direito autoral: Este artigo está licenciado sob os termos da Licença Creative Commons-Atribuição 4.0

Internacional.
(c) 